\title{
Making Safe Corridor by Engineering Interventions and Enforcement Interventions in Karnataka (India)
}

\author{
[Raj R.D. Kirori ${ }^{1}$, B.L. Swami ${ }^{2}$ ]
}

\begin{abstract}
Road fatalities in India have increased to 150,785 in year 2016. Karnataka, a major Indian state, appeared at $4^{\text {th }}$ rank with 11,133 road fatalities. Karnataka lost 17.8 persons per 100,000 population against India average of 11.9 persons. Karnataka is committed to road safety, therefore, in order to reduce road injuries by multi-sectoral interventions, an existing two lane undivided road section- Belgaum to Yaragatti (62 km)- was selected as a pilot project based on recommendations of iRAP (International Road Assessment Programme) under Safe Corridor Demonstration Programme (SCDP) funded by World Bank. Road crash data of the corridor were collected of past five years for analysis and proposed engineering designs were reviewed. Engineering interventions modified eight major junctions with medians, right turning lanes, 31 minor junctions with improved road signs and markings, construction of walkways with guard rails near most junctions, bus-bays and shelters, traffic calming, overall road marking and road signs. Enforcement interventions comprised two dedicated robust vehicles for the safe corridor with electronic evidence based speed interceptors, breath analyzers to curb drunken driving; GPS enabled handy cameras, hydraulic cutters for quick recovery of crash victims and signalization of three junctions. Engineering interventions were implemented by Karnataka State Highways Improvement Project (KSHIP). Enforcement interventions were implemented by Police department thru four police stations of the corridor. Outcome of interventions has resulted in reduction of fatalities and crashes by $50 \%$ and 20\% respectively from January 2017 to September 2017 corresponding months of 2016. Rapid increase in registering cases by Police for violations of traffic and driving rules, have resulted in increased compliance of speed limits and wearing of helmet by motorcyclists. Road crashes and injuries are expected to be reduced further upcoming implementation of public awareness and education campaign.
\end{abstract}

Keywords - safe corridor, road safety, road injuries, iRAP, traffic calming, engineering and enforcement interventions.

\section{Introduction}

Road injuries are globally recognozed as serious health issue and is more serious in India as road crashes and road fatalies (2016) were reported 480,652 and 150,785 repectively. Karnataka, a major Indian State, appreaed at $4^{\text {th }}$ rank with 11,133 road fatalities in 2016. Unfortunately most productive age group (18-35 years) shares $46.2 \%$ fatalities in India and $49.2 \%$ in Karnataka (2016).

Raj R.D. Kirori, Ph. D. Scholar,

Department of Civil Engineering,

Malaviya National Institute of Technology, Jaipur-302017, India

B.L. Swami, Professor,

Department of Civil Engineering,

Malaviya National Institute of Technology, Jaipur-302017, India
Karnataka lost 17.8 persons per 100,000 population against India average of 11.9 persons (2016) whereas United Kingdom average is below 3 only. The families of road crash victims suffer huge irreversible loss in terms of grief and deprival of family income. The State suffers substential productivity loss but these losses are preventatble. Karnataka State is commited to enhance road safety with multisector intervention to reduce road fatalities and crashes.

\section{Demo Safe Corridor}

\section{A. Purpose}

Purpose of safe corridor is to reduce road injuries by engineering corrections, intense enforcement to change traffic behaviour, awreness campaigns to change attitude of road users. This model and lessons learnt can be implemented on other State roads

\section{B. Background of the Pilot Project}

The Safe Safe Corridor Demostration Programme (SCDP) for enhancing road safety has been undertaken by Karnataka State Highways Improvement Project-II (KSHIPII) with World Bank assistance. A pilot project 'Belgaum to Yaragatti $(62 \mathrm{~km})$ was selected as demostration safe corridor.

The pilot 'safe corridor' project was selected for implementation on the basis of recommendations of International Road Assessment Programme (iRAP) after filed survey of $284 \mathrm{~km}$. This study was commissioned by World Bank in year 2011-12.

\section{Demo Safe Corridors in India}

The term 'Safe Corridor' is recently arrived in India. Presently three similar demostration projects in other States are completed or near completion. Therefore, standard procedures leading to multisector interventions including legal frameworks for safe corridors are yet to be formulated.

\section{Safe Corridors in US States}

The US States have defined criteria for designating a road segment as safe corridor. In principle a segment of road is designated as safe corridor if fatal and serious injuries crash rate is at or above 150 percent (Oregon State) of the statewide average for a similar road for past five years (Oregon State). The Alska considers crash rate 110 percent and period three years. In order to reduce fatalities and serious injuries in the designated safe corridor, multisector interventions are made mainly engineering corrections, enforcement imposing double fines under laws applicable to safe corridors and education /awarenessness campaigns. 


\section{Project Corridor}

This pilot demo safe corridor project from Belgaum to Yaragatti, is a $62 \mathrm{~km}$ section of an undivided 2-lane section of State Highway-20 comprising $22 \mathrm{~km}$ intermittently populated section, $3 \mathrm{~km}$ hill road and remaining $33 \mathrm{~km}$ in open area. The project falls in jurisdiction of four Police Stations responsible for enforcement.

\section{Engineering Interventions}

\section{A. Purpose}

Purpose of engineering intervention is to provide safer road elements based on forgiving designs at identified safety critical locations.

\section{B. Junctions}

Before project, there were no medians to prevent head on collisions on seven (out of eight) major junctions which included four Y-junctions. Seven junctions have been provided medians with right turning lanes to prevent rear hits.

Modified four Y-junctions to T-junctions shown in Fig 1and 2. A cross junction with right turning lanes at both ends is shown in Fig 3.

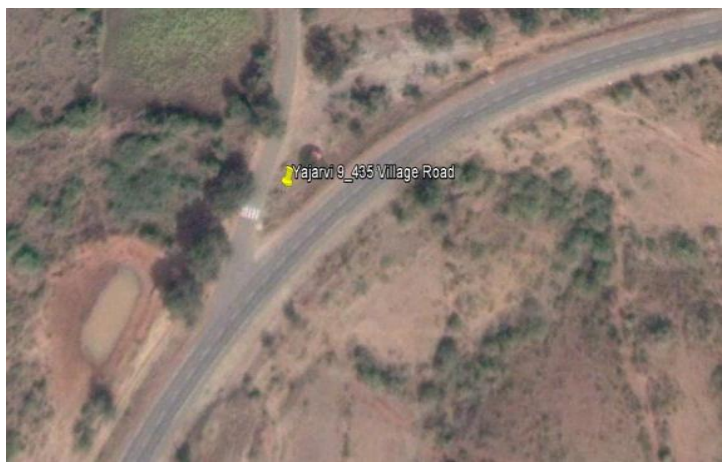

Figure 1 Before project Y-Junction Ch 9435

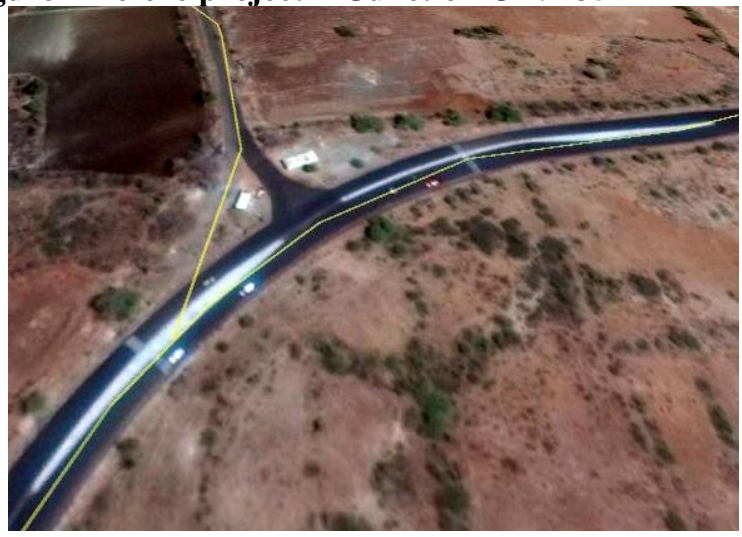

Figure 2 After project T-Junction with right turning lane Ch 9435

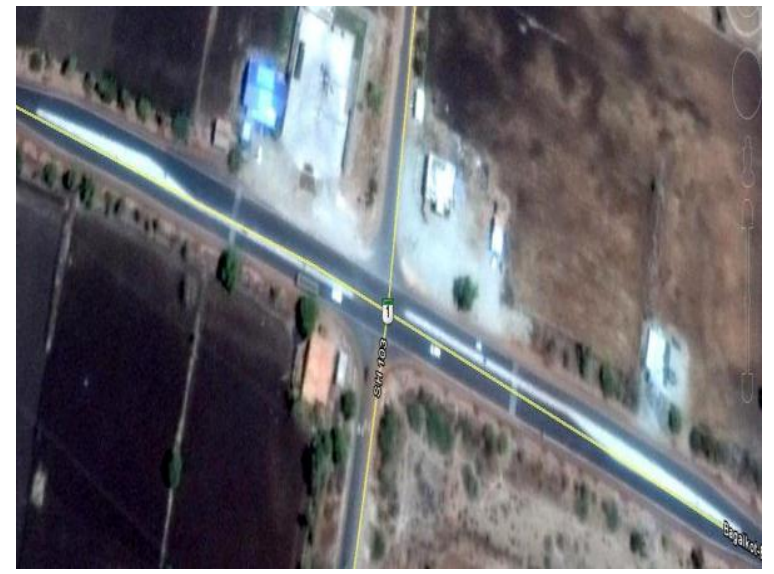

Figure 3 A cross junction provided with right turning lanes at both ends $\mathrm{Ch} 12760$

\section{Traffic calming}

Transverse Yellow bar marking (5 $\mathrm{mm}$ thick) boxes of thermoplastic road marking have been provided at eight major junctions to calm down traffic before reaching the junction and to change road environment to alert drivers at junctions arms. Fig 4 below shows bar marking.

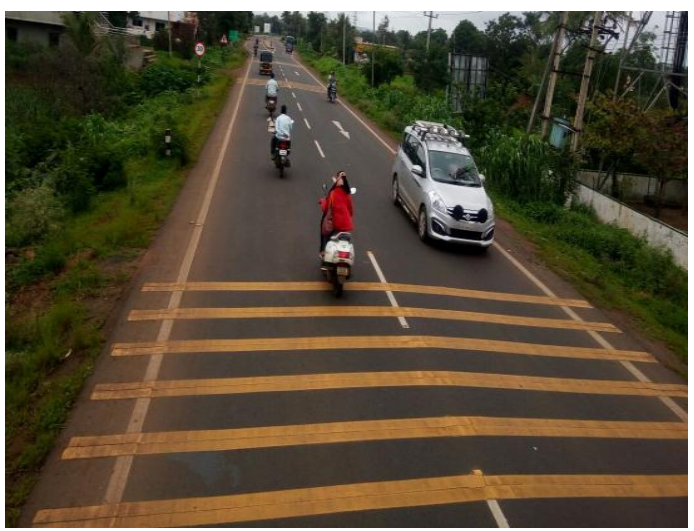

Figure 4 Transverse bar marking for traffic calming

Improvement/replacement of road signs and road marking on 31 minor junctions and road hump on minor roads.

\section{Pedestrians safety}

Raised pedestrian crossing (20 No.), footpaths with guard rails at major junctions/other locations and busbays /shelters at 13 locations have been provided.

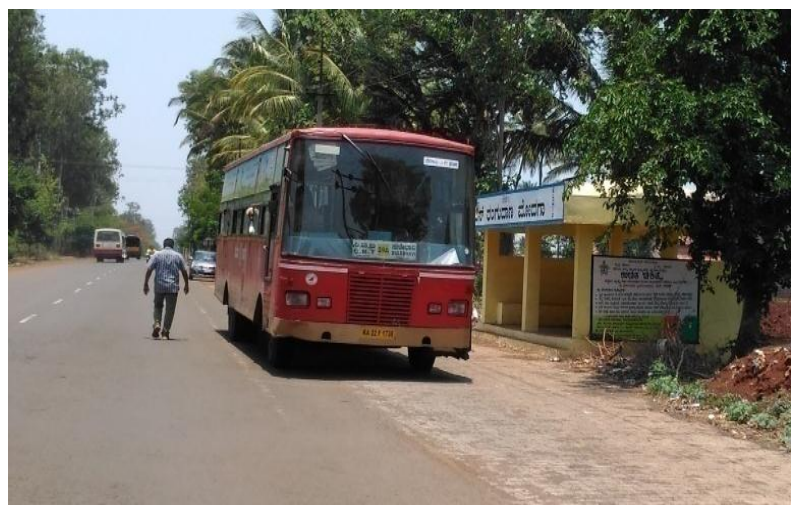

Figure 5 A bus bay and bus shelter at Ch 43257 


\section{E. Other Interventions}

Additional W-beam crash barriers (16000 meters) have been provided on curves and embankements to contain errant run off vehicles and to prevent from rolling down.

In hill section two overpassing zones, by constructing one additional lane, have been provided.

Additional lane has been provided at three locations for parking where parked vehicles congested carriageway.

Three major junctions have been signalised in consultation with Police.

Speed limit road signs have been installed in populated sections.

Delineations by road marking, chevron road signs in curves and raised pavement markers $(23,000$ No.) for traffic safety during night hours have been provided in the project. Summary of engineering interventions made on safe corridor is shown in Table 1 below.

TABLE I. SUMMARY OF ENGINEERING INTERVENTIONS MADE

\begin{tabular}{|l|l|l|}
\hline S.N. & Engineering Interventions. & Quantity \\
\hline 1 & $\begin{array}{l}\text { Major Junctions with median and right turning } \\
\text { lanes }\end{array}$ & 8 No. \\
\hline 2 & Transverse Bar Marking on all major junction & 8 No. \\
\hline 3 & $\begin{array}{l}\text { Improvement/replacement of road signs and } \\
\text { road marking and road hump on minor road }\end{array}$ & 31 No. \\
\hline 4 & $\begin{array}{l}\text { Raised pedestrian crossings and footpath at major } \\
\text { junctions and other locations. }\end{array}$ & 20 No. \\
\hline 5 & Bus bays/shelters & 13 No. \\
\hline 6 & Installation of additional W-Beam crash barriers & $16000 \mathrm{~m}$ \\
\hline 7 & Overpasses in hill sections & 2 No. \\
\hline 8 & Addition lane for parking in congested locations & 3 No. \\
\hline 9 & Signalisation of junctions & 3 No. \\
\hline 10 & Raised Pavement Markers on road markings & 23000 No. \\
\hline
\end{tabular}

\section{v. Police Enforcement Interventions}

\section{A. Purpose}

The objective of enforcement is to change traffic behaviour and attitude of road users for compliance of driving rules, particularly overspeeding, drunken driving, use of helmets and seat belts.

\section{B. Resources provided to Police}

The Police have been provided additional equipment, tools, traffic management accessories procured by the road agency for this safe corridor project and delivered to four Police Stations having jurisdiction on the project.

Resources provided for enforcement of speed limits, alcohol limits, driving and traffic rules to prevent crashes are as under:
- Two dedicated car mounted interceptors, roof top surveillance camera are shown in Fig 6.

- Alcohol Breath Analysers (4 No.) for four stations

- Laser speed guns (4 No.) for four stations

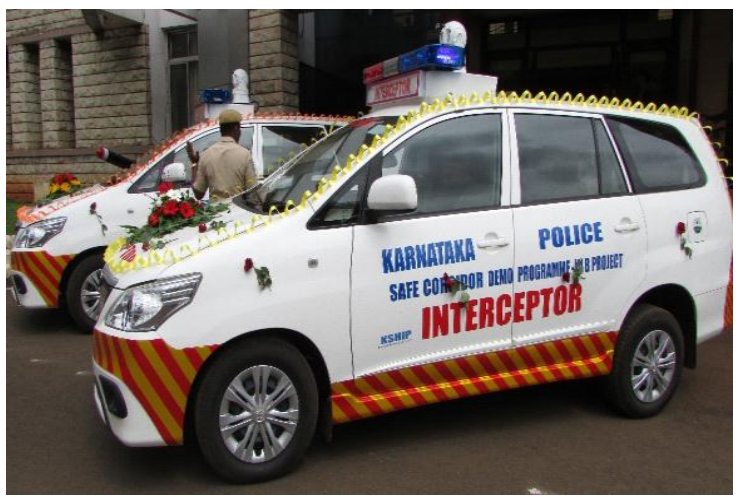

Figure 6 Speed Interceptors

For post crash response to rescue crash victim from vehicles and first aid.

- Hydraulic cutting/spreading tools for rescue (2 No.)

- Automated External Defibrillators (life saving equipment)

For crash investigation and documentation.

- Digital cameras GPS enabled (4 No.)

- $\quad$ Video cameras (4 No.)

For traffic management and miscellaneous devises

- Traffic separators, delineator cones (200 No.)

- $\quad$ Reflective jackets (120 No.)

- Fluorescent batons (25 No.)

- $\quad$ First aid boxes (20 No.)

- Search lights (12 No.)

\section{Police Workshops and trainings conducted}

In order to make best use of equipment and tools and orientaion of Police staff, interactive workshops and practical training in field were conducted at Police Station level to associate maximum staff members. (Fig 7 and Fig 8)

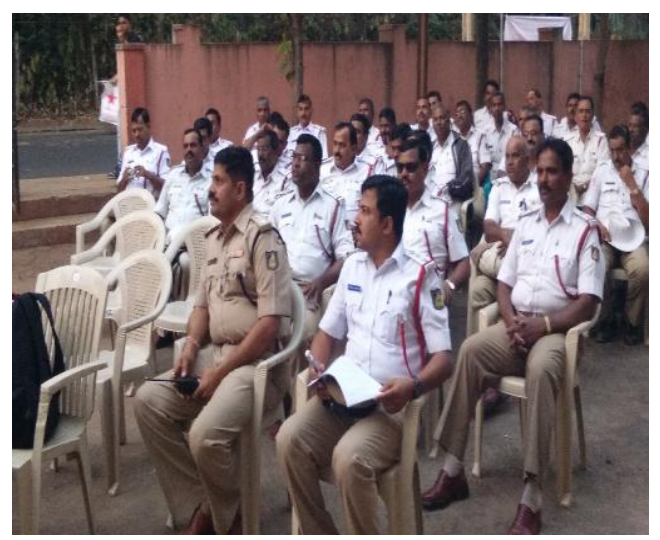

Figure 7 Police Work shop in progress 


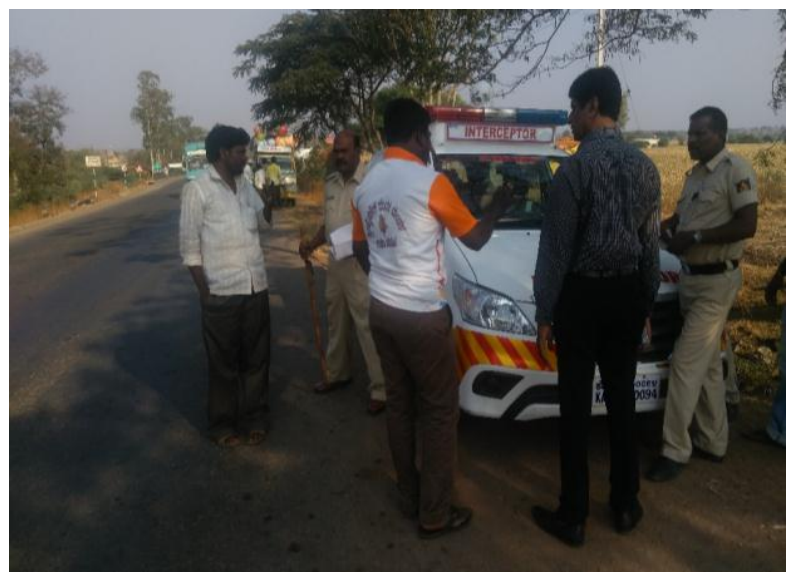

Figure 8 Enforcement Trainings in field

\section{Enforcement tasks}

Mere presence of Police on the project road is itself enforcemement as road users themselve become attentive and comply rules. Police mainly focus on violation of traffic and driving rules and following common traffic offences which commonly become cause of road crashes:

- Over-speeding - speed is a core issue in road crash

- Drunken driving

- Driving 2-wheeler without wearing helmet

- Driving cars without wearing seatbelt

- Using mobile phone while driving

- Over crowed school children in Auto/Vans

- Over crowed buses/other passengers vehicles

- Carrying passengers in goods vehicle.

\section{E. Outcome of Police Enforcement}

Upgraded enforcement with evidence based electronic equipment and active presence of Police on the safe corridor, resulted in steep rise in booked cases as shown in Fig 9. Fear of being booked, road users are changing traffic behaviour.

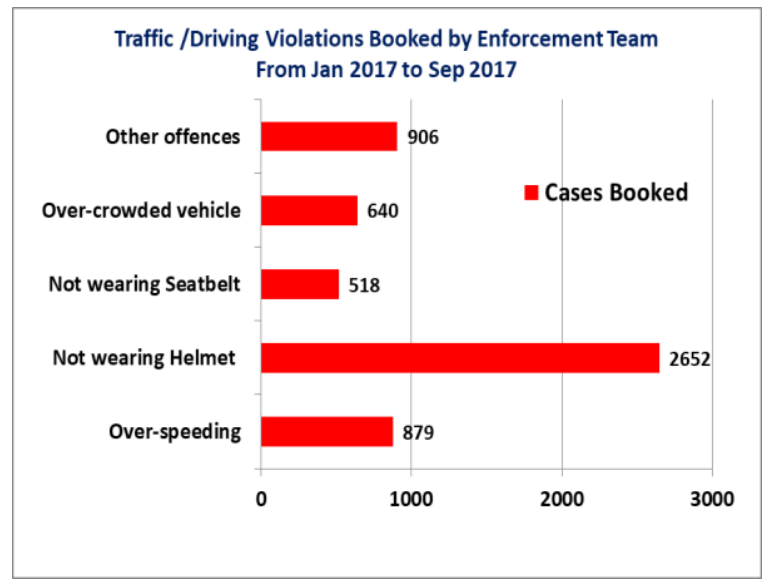

Figure 9 Traffic/Driving Violations (Jan 17 to Sep 17)

\section{vi. Outcome of Engineering and Enforcement Interventions}

The outcome of engineering and enforcement is visible as road users are guided by road delineations and improved road engineering and at the same time road user is alert due to presence of Police and cameras.

Road fatalities have recorded steep fall during January 2017 to September 2017 in comparison to corresponding months of year 2016. The data are presented in Fig 10 below:

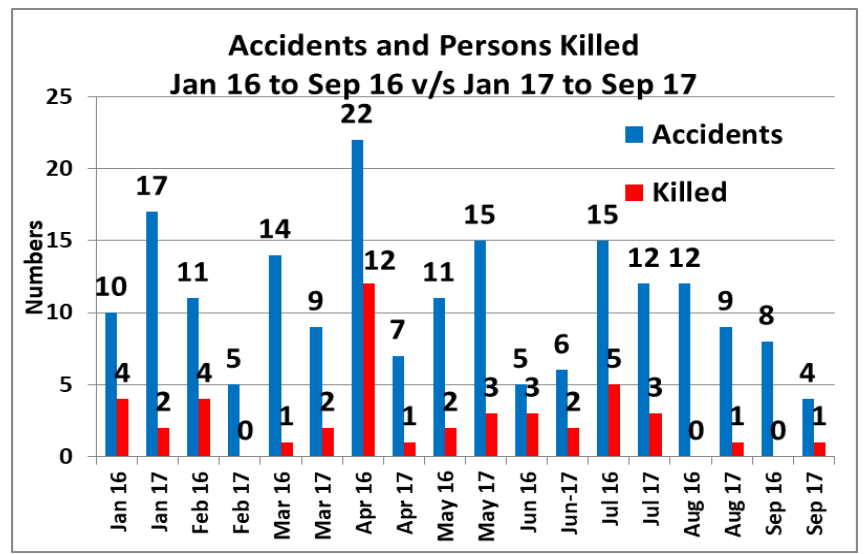

Figure 10 Comparison of Accidents and persons killed

Jan 2016 to Sep 2016 v/s Jan 2017 to Sep 2017

The outcome summary of total road crashes and persons killed between January 2017 to September 2017 with total of corresponding months of year 2016, is presented in Fig 11 below:

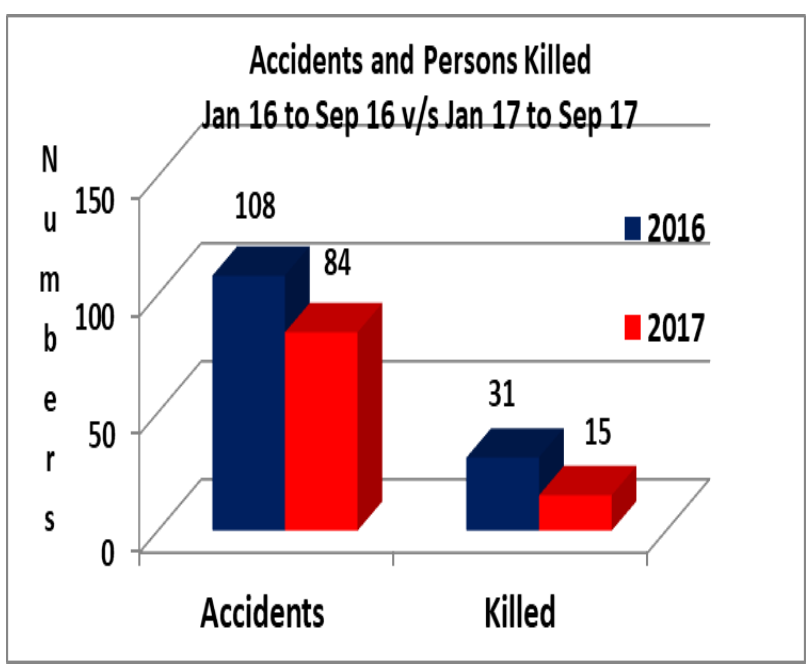

Figure 11 Reduction in road fatalities in Jan 2017 to Sep 2017 corresponding months of year 2016

The outcome reveals that reduction in road crashes is 22 percent and reduction in fatalities is 50 percent between January 2017 to September 2017 with total of corresponding months of year 2016 which shows a positive and encouraging trend.

\section{vII. Conclusions}

The outcome of engineering and enforecment interventions show sharp reduction in road crashes and road 
fatalities by 22 percent and 50 percent respectively. In fact engineering and enforcement interventions still have scope of further improvement based on lessons learnt during implementation.

A detailed plan of road safety awareness campaigns for road users and implementation plan is nearly ready and expected to be commenced in couple of months. The objective awareness campaigns (i) make awre of current road crash fatalities and injuries in the country and State and (ii) to change attitude of road users for traffic safety and compliance.

A further reduction in crashes, fatalities and serious injuries is expected if interventions of other sectors are planned and implemented by the stakeholders namely heath, education and transport in the safe corridor while coordinating with road agency and Police.

\section{References}

[1] Road Accidents in India-2016, published by Ministry of Road Transport \& Highways, Transport Research Wing, New Delhi, India

[2] iRAP India Four States Road Safety Report:Technical Overview, preprared by International Road Assessment Programme, 2011

[3] Oregon Safety Corridor Guidelines, January 2017, Oregon Department of Tranportation, Safety Division

[4] Systhesis Study on Effectiveness of Safety Corridors Programme, Final Report July 2008 , Centre for Transportation Research and Education, Iowa University

[5] Manual of Specifications and Standards for Two Lanning of Highways with Paved Shoulders, Indian Roads Congress, IRC:SP:732015

[6] Code of Practice for Road Marking (Second Revision), Indian Roads Congress, IRC:35-2015

[7] Code of Practice for Road Signs (Third Revision), Indian Roads Congress, IRC:67-2012

[8] Manual on Road Safety, Indian Roads Congress, IRC:SP:88-2010 